\title{
Lapidação de mediadores de leitura e sujeitos leitores para o protagonismo social
}

\author{
Raquel do Rosário Santos \\ Universidade Federal da Bahia, Instituto de Ciência da Informação, Salvador, BA, Brasil \\ quelrosario@gmail.com \\ Ana Claudia Medeiros de Sousa \\ Universidade Federal da Bahia, Instituto de Ciência da Informação, Salvador, BA, Brasil \\ ana.violista@gmail.com \\ Ingrid Paixão de Jesus \\ Universidade Federal da Bahia, Instituto de Ciência da Informação, Salvador, BA, Brasil \\ ingridpaixao191@gmail.com
}

DOI: https://doi.org/10.26512/rici.v13.n1.2020.22932

Recebido/Recibido/Received: 2019-02-14

Aceitado/Aceptado/Accepted: 2019-11-11

Resumo: A leitura amplia a possibilidade de o sujeito alcançar novos horizontes como um ser crítico socialmente construído. Nesse contexto, a biblioteca comunitária é entendida como um ambiente acolhedor e que apoia seus usuários em relação à busca da informação, ao acesso a ela, ao seu uso e à apropriação. Quanto às atividades de extensão na universidade, proporcionam a aproximação e o diálogo entre a comunidade acadêmica e a população. Objetivo: Investigar a trajetória da realização do projeto de extensão sobre a mediação da leitura, no contexto da biblioteca comunitária, visando formar mediadores da leitura e sujeitos leitores. Embasamento teórico: A pesquisa foi ancorada nas concepções teóricas de Almeida Júnior (1997, 2014), Gomes (2014, 2017), Petit (2008) e Carvalho (2005), entre outros, que compreendem a mediação da leitura como uma ação essencial para formar sujeitos críticos e protagonistas. Metodologia: Foi feita a observação direta, durante as ações de extensão, utilizando como instrumento o diário de campo. No que diz respeito à coleta de dados, foi aplicado um questionário para os integrantes do 'Projeto Lapidar', composto de discentes e egressos dos Cursos de Biblioteconomia e Arquivologia. Resultados: O estudo mostrou que é importante qualificar mediadores da leitura e elaborar projetos de extensão que propiciem a execução de ações de mediação da leitura. Conclusão: É preciso formar e fortalecer redes de colaboração e parceria entre a universidade e a comunidade, que conta com os ambientes informacionais para apoiar a formação de mediadores de leitura e sujeitos leitores.

Palavras-chave: leitura. mediação da leitura. biblioteca comunitária. extensão universitária. biblioteca universitária.

\section{Lapidation of reading mediators and subject readers for social protagonism}

Abstract: Reading expands the possibility of the subject reaching new horizons while being socially constructed critical. Thus, we understand the role of the community library as a welcoming environment that supports the search, access, use and appropriation of users' information. As for extension activities at the university, they provide rapprochement and dialogue between the academic community and the population. Objective: To investigate the trajectory of the realization of the extension project on reading mediation in the context of the community library, aiming at the formation of reading mediators and reading subjects. Theoretical background: it was based on the theoretical conceptions of Almeida Júnior 
(1997, 2014), Gomes (2014, 2017), Petit (2008), Carvalho (2005), among others who understand reading mediation as an essential action for the formation of students. critical subjects and protagonists. Methodology: consisted of direct observation during extension actions, using the field diary as an instrument. Also, regarding data collection, we used the technique of applying a questionnaire to the members of the Lapidar Project composed of students and graduates of the Library and Archivology courses. Results: it was observed the importance of qualifying reading mediators, reinforcing the relevance of the elaboration of extension projects that allow the execution of reading mediation actions. Conclusion: It is necessary to form and strengthen collaboration and partnership networks between the university and the community, which has informational environments to support the formation of reading mediators and reading subjects.

Keywords: reading. reading mediation. community library university extension. university library.

\section{Lapidación de mediadores de lectura y sujetos lectores para el protagonismo social}

Resumen: La lectura amplía la posibilidad de que el sujeto alcance nuevos horizontes mientras se construye socialmente crítico. Por lo tanto, entendemos el papel de la biblioteca comunitaria como un entorno acogedor que apoya la búsqueda, el acceso, el uso y la apropiación de la información de los usuarios. En cuanto a las actividades de extensión en la universidad, proporcionan un acercamiento y diálogo entre la comunidad académica y la población. Objetivo: Investigar la trayectoria de la realización del proyecto de extensión sobre mediación de lectura en el contexto de la biblioteca comunitaria, con el objetivo de formar mediadores de lectura y temas de lectura. Antecedentes teóricos: se basó en las concepciones teóricas de Almeida Júnior (1997, 2014), Gomes (2014, 2017), Petit (2008), Carvalho (2005), entre otros que entienden la mediación lectora como una acción esencial para la formación de los estudiantes. sujetos críticos y protagonistas. Metodología: consistió en la observación directa durante las acciones de extensión, utilizando el diario de campo como instrumento. También con respecto a la recopilación de datos, utilizamos la técnica de aplicar un cuestionario a los miembros del Proyecto Lapidar compuesto por estudiantes y graduados de los cursos de Biblioteca y Archivología. Resultados: se observó la importancia de calificar a los mediadores de lectura, lo que refuerza la relevancia de la elaboración de proyectos de extensión que permitan la ejecución de acciones de mediación de lectura. Conclusión: es necesario formar y fortalecer redes de colaboración y asociación entre la universidad y la comunidad, que cuenta con entornos informativos para apoyar la formación de mediadores de lectura y materias de lectura.

Palabras-clave: lectura. mediación de la lectura. biblioteca comunitaria. extensión universitaria. biblioteca universitaria.

\section{Introdução}

Atualmente, o cenário nacional passa por uma carência no que diz respeito à formação de leitores. O leitor não é apenas aquele que decodifica signos, mas que interpreta, compreende e atua para mudar seu espaço social. Nesse contexto, o bibliotecário tem uma responsabilidade significativa no que tange à mediação da informação e à formação de leitores.

Percebe-se que são necessárias ações para qualificar o bibliotecário, como mediador da leitura, sobretudo, de se promover essa formação ainda quando estudantes de Biblioteconomia. Nessa perspectiva, esta pesquisa teve como objetivo geral investigar a trajetória de realização do projeto de extensão sobre a mediação da leitura no contexto da biblioteca comunitária, com vistas à formação de mediadores da leitura e de sujeitos leitores. 
Essa comunicação se configura como descritiva e qualitativa e relata a experiência do desenvolvimento do Projeto Lapidar, que é exemplo de uma demanda por parte dos discentes de Biblioteconomia e de Arquivologia para a reflexão, a formação e o exercício da prática de mediação da leitura no ambiente acadêmico. Essa iniciativa reforça que, além de a teoria auxiliar a formar esses profissionais, a prática e o contato com a comunidade proporcionam a construção de conhecimentos, por meio da vivência e da identificação de necessidades informacionais, que estimulam a utilização de métodos apresentados na academia para auxiliar os sujeitos a se desenvolverem.

O objetivo do Projeto Lapidar foi de desenvolver ações de formação de leitores e de mediadores da leitura. Para alcançar esse objetivo, foram desenvolvidas ações de mediação da leitura - as que envolveram todas as atividades que auxiliaram o processo de formação do leitor e o desenvolvimento do gosto pela leitura, por exemplo, contação de histórias, roda e experiência de leitura, imagem em ação (atividade a partir de vídeos e leitura escrita) e vestígios de memórias (encontros intergeracionais). Nessa dinâmica, observou-se que, de um lado, os estudantes de Biblioteconomia e de Arquivologia colocaram em prática o que foi apreendido na Universidade, e, de outro, a comunidade pôde ter acesso a ações e práticas de leitura, que os auxiliaram a adquirir o prazer de ler.

O ambiente em que a atividade de extensão foi realizada foi a Biblioteca Comunitária Padre Affonso Pacciani, localizada na Fazenda Grande do Retiro, em Salvador, na Bahia. As ações desenvolvidas nessa biblioteca - de formação de mediadores - foram divididas em quatro etapas: a de qualificação dos estudantes na Universidade Federal da Bahia; a de planejamento das ações de mediação, o que propiciou a terceira etapa- a de realização das ações de mediação da leitura na comunidade - e a de avaliação dessas ações e da qualificação dos mediadores por intermédio do questionário, instrumento utilizado na coleta de dados. Assim, foi possível concluir, a partir das atividades previstas e citadas acima, que seria preciso promover a aproximação e o fortalecimento de redes entre a comunidade acadêmica e a Biblioteca Comunitária, mediada pelas ações de extensão.

\section{Leitura e mediação}

Sabe-se que o domínio da leitura é fundamental, posto que propicia o desenvolvimento do vocabulário; facilita a obtenção de conhecimentos; proporciona o entendimento lógico; amplia a capacidade de interpretar e desenvolve a capacidade comunicativa. Portanto a leitura contribui para que o sujeito desenvolva os aspectos cognitivos, culturais e sociais. 
Quanto ao gosto pela leitura, Carvalho $(2005$, p. 67) compreende que "[...] algumas pessoas criam o gosto pela leitura pelo exemplo de familiares, outras por influência de professores ou por circunstância fortuitas de suas histórias de vida." Assim, o desenvolvimento do hábito de ler e o gosto pela leitura requerem ações que propiciem a formação do sujeito leitor. Para isso, espaços como bibliotecas são propícios para o desenvolvimento de ações de formação de leitores, para que crianças, jovens, adultos e idosos sintam-se motivados a essa prática.

Kato $(1999$, p. 8) afirma que, “[...] uma vez iniciado o processo da aquisição da leitura e da escrita, parece haver uma interferência recíproca, de forma que quanto mais se lê melhor se escreve, e quanto mais se escreve melhor se lê." Isso significa que, quanto mais o sujeito tem contato com os livros, entre outros materiais informacionais, mais se habitua a ler, o que poderá propiciar condições para que ele escreva melhor, amplie seu vocabulário e se comunique com mais facilidade.

O contato com o livro proporciona ao leitor uma experiência valiosa, porquanto amplia seus conhecimentos, o que torna o livro mais que uma fonte de informação, já que estimula o prazer por meio dos diversos gêneros literários. Convém enfatizar que não é só o livro que conduz à leitura, porque outros materiais informacionais, se forem mediados com efetividade, poderão proporcionar isso. Um filme pode despertar a leitura de uma obra; uma música pode motivar o sujeito a pesquisar o contexto sociocultural da composição musical, e os materiais iconográficos podem revelar indícios de fatos que também remetem à leitura e a novas descobertas. Assim, a leitura, em suas diversas percepções, formatos e tempos, deve ser o centro das discussões que conduzem ao desenvolvimento do leitor.

A leitura possibilita ao indivíduo alcançar novos horizontes, como ser crítico socialmente construído. Entretanto, sabe-se que, para formar o leitor e proporcionar seu desenvolvimento crítico, as colaborações da família, da sociedade e do Estado são essenciais para garantir os meios de acesso à educação, à informação e à leitura, posto que "[...] a informação e o conhecimento se transformam, cada vez mais, em importantes fatores de transformações econômicas e sociais" (BARBOSA, 2008, p. 13).

Bortolin (2010, p. 112) compreende que existem mais do que cinco sentidos naturais e que o sexto é "[...] a leitura, [que] será exercida ou não, dependendo da situação econômica, política, social de cada indivíduo." Esse sentido será estimulado por meio de uma sociedade consciente de seus deveres e responsabilidades sobre a construção de um espaço social, propício para o desenvolvimento de um sujeito crítico. Por isso, professores, bibliotecários, contadores de histórias e todos os que, de alguma forma, influenciam o processo da leitura, atuam na interferência casual ou planejada desse possível leitor. 
Sobre o processo de mediação da leitura, Michele Petit (2008, p. 139) afirma que "[...] não é a biblioteca ou a escola que desperta o gosto por ler, aprender, imaginar, descobrir. É um professor, um bibliotecário, que, levado por sua paixão, a transmite através de uma relação individual." E mesmo que não existam condições políticas, econômicas e de infraestrutura, a proatividade do mediador poderá ser transformada em ações de relevância para o desenvolvimento dos sujeitos leitores. Assim, as barreiras citadas, em alguns casos, são superadas com a atuação de sujeitos protagonistas, que, apesar das dificuldades, conseguem realizar ações de mediação, que formam redes colaborativas, propiciam a captação de recursos para isso e passam a ser motivadoras e referências para que outras ações possam ser desenvolvidas.

Refletindo sobre o conceito de mediação da informação, Almeida Júnior diz

[...] que a mediação da informação está diretamente ligada às ações implícitas e explícitas, voltadas para o usuário, e que a mesma é fundamental nas práticas do profissional da informação. O caráter da mediação depende não somente das ações realizadas pelos bibliotecários, como também da presença imediata/ física ou não dos usuários. (ALMEIDA JÚNIOR, 2014, p. 101).

Aproximando esse conceito do contexto da leitura, pode-se conceber o bibliotecário como um profissional que deve ser leitor e que potencializa a leitura. Em suas atividades de mediação indireta, ele faz uma leitura para reconhecer a obra que Ihe possibilita identificar, extrair e traduzir termos descritores e representativos, o que demonstra que, embora a leitura inicie tecnicamente, ela alcança um nível analítico e interpretativo. Nesse contexto das ações indiretas, o bibliotecário leitor não dialoga com os usuários, mas prepara os materiais informacionais para serem consultados e utilizados por eles. Mais amplamente, pode-se dizer que o bibliotecário se prepara para aproximar o usuário da leitura, quando assume ações diretas, dialogando e interagindo com ele na perspectiva de ações de leitura. Assim, as ações de mediação da informação também são, essencialmente, ações diretas e indiretas de leitura.

Há, ainda, várias possibilidades e níveis de mediação direta de leitura, que, para além das tradicionais, como as que acontecem nos setores de referência, quando o bibliotecário indica leituras e dialoga com o usuário sobre elas, a mediação pode alcançar um nível mais amplo, quando é independe do tipo de biblioteca, como, por exemplo, as universitárias e as especializadas, que promovem encontro com o autor, rodas de leitura e debates sobre temas constantes em seus acervos. Nesse sentido, a mediação da leitura passa para um nível mais alto e envolve, de maneira macro, os usuários e a própria instituição a que está vinculada, favorecendo a ambiência para o acesso, o uso e a apropriação da informação. 
É possível afirmar que a mediação da informação e da leitura está presente no âmbito da biblioteca, como ações que conduzem a dois vieses: o primeiro é o mediador que influencia o mediado, e o outro, é o mediado, que não só foi influenciado pelo mediador, como também o influenciou por meio de suas ânsias e desejos, o que ressignifica a mediação a partir de um caráter dialógico, em que as experiências humanas dependem das práticas de comunicação, como afirma Gomes (2014, p. 49):

\begin{abstract}
Essa compreensão revela a mediação como um processo dialético que exige do agente mediador uma disposição e preparação para atuar no respeito a essa condição fundante da ação mediadora. $\mathrm{E}$, ao mesmo tempo, ser capaz de se autoavaliar, buscando seu autoconhecimento para superação de seus próprios limites, mas também para se colocar como um sujeito implicado no processo, que se responsabiliza por ele, aperfeiçoando seu próprio perfil protagonista.
\end{abstract}

Assim, a mediação está diretamente ligada à ação da comunicação realizada pelos sujeitos e às suas experiências, o que é uma condição indispensável à formação do protagonismo social, em que todos os interlocutores constituem esse processo que, de acordo com a compreensão de Gomes (2017, p. 38), pode favorecer o aperfeiçoamento das ações nele realizadas e o desenvolvimento de novas experiências no âmbito de suas ações mediadoras.

\title{
3 As bibliotecas comunitárias como ambientes propícios para as ações de extensão
}

As bibliotecas são ambientes de mediação da informação propícios para a realização de ações que promovem o acesso aos recursos bibliográficos. Independentemente do seu tipo, seja escolar, universitária, entre outros, disponibiliza espaço e coleções para atender às demandas informacionais dos usuários leitores, ou seja, a biblioteca oferece serviços, técnicas de tratamento, gerenciamento de recursos informacionais e estratégias de mediação, com o intuito de promover e garantir acesso, uso e apropriação da informação.

Em se tratando da biblioteca comunitária, devido à maneira como atua, promove o acesso à informação para diferentes perfis de usuários que compõem sua localidade e busca, incansavelmente, contribuir, por meio de estratégias de mediação da informação, para formar leitores críticos, capazes de exercer a cidadania em sua plenitude.

Almeida Júnior (1997) compreende que as bibliotecas públicas e as comunitárias têm os mesmos objetivos e argumenta que

[...] o adjetivo comunitário estaria sendo empregado com o intuito de destacar essa proposta de outras tantas existentes, tornando-a mais atraente, inclusive para a sociedade que, em função dessa nova designação, pode imaginá-la tratando-se de uma instituição diferente da biblioteca pública sobre a qual já possui um estereótipo formado. Assim a biblioteca comunitária passaria para a sociedade, por uma nova entidade, não 
carregando preconceitos e idéias preconcebidas que prejudicariam sua atuação. (ALMEIDA JÚNIOR, 1997, p. 107).

Ressalte-se, entretanto, que, apesar de concordar com alguns pontos elencados por Almeida Júnior (1997), Machado (2009) identifica particularidades que julga distinguir a biblioteca comunitária da biblioteca pública. Para tanto, aponta os aspectos que considera inerentes à biblioteca comunitária, a saber:

1. a forma de constituição: são bibliotecas criadas efetivamente pela e não para a comunidade, como resultado de uma ação cultural.

2. a perspectiva comum do grupo em torno do combate à exclusão informacional como forma de luta pela igualdade e justiça social.

3. o processo participativo gerando articulação local e forte vínculo com a comunidade.

4. a referência espacial: estão, em geral, localizadas em regiões periféricas.

5. o fato de não serem instituições governamentais, ou com vinculação direta aos Municípios, Estados ou Federação. (MACHADO, 2009, p. 88-89).

A autora citada compreende a biblioteca comunitária como um tipo específico de biblioteca, uma vez que sua criação parte de princípios de autonomia e articulação local de populares. Essa reflexão denota que a maneira como os sujeitos se relacionam com a biblioteca é distinta e que a biblioteca comunitária nasce dos anseios, dos desejos e das expectativas dos sujeitos. Assim, eles compreendem esse ambiente como seu e o reconhecem como equipamento cultural transformador, em que é possível realizar suas ações e ter espaço de fala.

A maioria dos usuários de bibliotecas comunitárias são sujeitos que estão à margem de acesso aos outros tipos de biblioteca. Nessa conjuntura, a própria população dedica esforços para mudar a realidade de marginalização de seu grupo social, pois reconhece que "[...] a biblioteca tem tudo para estar na vanguarda da luta contra a exclusão social" (MACHADO, 2005, p. 114). A biblioteca comunitária é reconhecida como um ambiente que potencializa a transformação da realidade social e é essencial para formar sujeitos críticos e protagonistas.

Uma das estratégias significativas que as bibliotecas comunitárias utilizam, como ambiente transformador, é o apoio à formação de leitores. Nesse sentido, desenvolve ações de mediação da leitura, porque esse tipo de biblioteca desenvolve atividades que incluem a formação do acervo com coleções diversas, organiza o perfil de seu usuário e disponibiliza, divulga e promove a circulação desses itens informacionais. Suas ações também são planejadas e desenvolvidas de maneira singular e pensadas e realizadas por membros da própria comunidade. Assim, as atividades e as ações de mediação da informação e da leitura demonstram características próprias em todo o fluxo informacional e a interação dos sujeitos nesse processo. 
Em alguns casos, as bibliotecas comunitárias buscam e/ou acolhem parceiros para oferecer produtos e serviços e realizar ações que estimulam o gosto pela leitura e o hábito de ler. Por essa razão, devem-se construir redes de colaboração para efetivar essas ações, como, por exemplo, os projetos de extensão universitária, que ultrapassam os muros acadêmicos e propiciam à comunidade estratégias de aprimoramento de suas práticas cotidianas.

A universidade é considerada um espaço de produção de conhecimentos cujos pilares essenciais são o ensino, a pesquisa e a extensão. A extensão pode ser compreendida como um conjunto de ações realizadas pela comunidade acadêmica, que se fundamentam na prática do ensino-aprendizagem e na pesquisa. Garrafa (1988, p. 109) compreende a extensão como "[...] um processo educativo, cultural e científico que articula o ensino e a pesquisa de forma indissociável e viabiliza a relação transformadora entre universidade e sociedade." Assim, uma das significativas características das atividades de extensão é de propiciar a interação entre os sujeitos que perpassa os muros da universidade.

Vale ressaltar que é sobremaneira importante realizar projetos e atividades de extensão, como um instrumento que a universidade usa para interferir e modificar a realidade social e um meio de possibilitar a aproximação com a comunidade e democratizar e ampliar o conhecimento e expandi-lo para os lugares mais diversificados. Dessa maneira, a extensão pode ser reconhecida como uma ponte mediadora entre a universidade e a comunidade que se ressignificam mutuamente.

\section{Metodologia}

Esta comunicação se caracteriza como descritiva, de natureza qualitativa, cujo objetivo geral foi o de investigar a trajetória de realização do projeto de extensão sobre a mediação da leitura no contexto da biblioteca comunitária, com vistas à formação de mediadores da leitura e sujeitos leitores. Para isso, foram traçados os seguintes objetivos específicos: descrever as atividades de mediação da leitura e investigar as contribuições do Projeto de Extensão Lapidar para os discentes e egressos, integrantes do Projeto, na perspectiva de suas ações em estágios, trabalho e/ou compreensão do exercício de um futuro profissional da informação.

O Projeto de Extensão Lapidar surgiu da necessidade de promover atividades que potencializassem a formação de mediadores da leitura e apoiassem o desenvolvimento do gosto pela leitura e do hábito de ler, por meio da aproximação entre a comunidade acadêmica e a biblioteca comunitária e seus integrantes. O Projeto foi realizado a partir do contato com a Rede de Bibliotecas Comunitárias, que reúne 14 instituições na capital baiana. Porém sua interferência se iniciou na Biblioteca Comunitária Padre Affonso Pacciani, localizado no Bairro de Fazenda Grande do Retiro. Foi desenvolvido no primeiro semestre de 2017, com encontros 
semanais, que iniciaram na Universidade Federal da Bahia e, posteriormente, na Biblioteca Comunitária. Para alcançar os objetivos propostos pela pesquisa, foi utilizado como instrumento de coleta de dados o diário de campo, para proceder à observação direta, como também o questionário com três perguntas, todas abertas e direcionadas aos discentes e aos egressos - duas bibliotecárias egressas do Curso de Biblioteconomia - e cinco estudantes de graduação de Biblioteconomia e de Arquivologia.

Para proporcionar conforto aos discentes e aos egressos, no que tange à análise e à avaliação das ações, para que eles pudessem expressar suas opiniões de maneira espontânea, optou-se pela aplicação do questionário, que foi enviado por e-mail. A primeira etapa - a de análise das atividades - ocorreu durante a execução do projeto, e a aplicação do questionário, depois da conclusão das atividades na Biblioteca Comunitária Padre Afonso Pacciani. Quanto à análise dos resultados, foi adotada a abordagem qualitativa, para interpretar as respostas dos sujeitos participantes.

\section{Apresentação e análise dos resultados}

Antes de fazer uma análise sobre o desenvolvimento da qualificação dos estudantes que participaram do projeto e a construção da parceria que proporcionou essa ação, é preciso falar sobre como foi o processo de constituição do grupo de participantes, ou seja, como os oito membros identificaram e integraram a equipe do projeto.

O projeto foi divulgado em sala de aula, entre membros de grupo de pesquisa, através de mensagens nos recursos comunicacionais direcionadas à comunidade e convites - tanto de maneira individual quanto coletiva - nos ambientes acadêmicos. Entretanto a conquista da participação dos discentes foi realizada, de fato, a partir da ação, quando eles assistiram às primeiras palestras e se identificaram com o tema e a proposta do projeto. Devido à falta de recursos financeiros, de bolsas e de ajuda de custo, os discentes participaram voluntariamente e, apesar das dificuldades individuais, comprometeram-se com o projeto. Assim, a equipe foi composta de dez membros - três docentes e duas bibliotecárias egressas do Curso de Biblioteconomia - e cinco estudantes de graduação - quatro do Curso de Biblioteconomia e um do Curso de Arquivologia.

\subsection{Realização das atividades de mediação da leitura por meio de ação de extensão}

A primeira etapa realizada do projeto foi a qualificação dos estudantes. Para isso, foi preciso identificar pesquisadores, profissionais e/ou especialistas que, voluntariamente, falassem sobre suas experiências e vivências e demonstrassem algumas técnicas e métodos de realização da mediação da leitura. Essas três colaboradoras proferiram palestras sobre a 
mediação da leitura, não só para os integrantes do grupo, mas também para a comunidade acadêmica.

As palestrantes propiciaram momentos de muita aprendizagem e interação com os discentes, e suas palestras favoreceram o acesso às informações e à construção de novos conhecimentos sobre mediação da leitura. No término de cada ação, houve entusiasmo e expectativa, sobretudo por parte de cada membro da equipe, além do desejo de praticar ações de mediação da leitura.

A etapa seguinte consistiu em planejar as ações de mediação da leitura, com o objetivo de identificar as habilidades individuais e colocar em prática o que cada integrante aprendera na fase de qualificação. Para isso, houve reuniões em que os membros sugeriram ações de mediação da leitura ligadas às suas habilidades e competências. Também foi selecionado o público para quem a ação seria direcionada. Tanto o levantamento e a identificação das habilidades e competências quanto o perfil do público da biblioteca comunitária auxiliaram o desenvolvimento das atividades de mediação.

Depois defeito o planejamento, houve ações de mediação da leitura na comunidade. Nos encontros semanais, que aconteciam na Biblioteca Comunitária, realizaram-se as seguintes atividades: contação de histórias, associadas à elaboração de desenhos e pinturas pelas crianças; peça teatral, que propiciou a produção de texto; exposição de filme com debate; declamação de poema; brincadeira se doação de livros. Foi proposto que a experiência continuasse, com o empréstimo de livros do acervo pertencente à biblioteca.

Ao encerrar cada ação, os membros do projeto se reuniam para avaliar a atividade, com o objetivo de identificar os pontos positivos e fortalecê-los e de melhorar as ações. Além das avaliações parciais, também se fez a avaliação final, e os membros, por meio da aplicação do questionário, apresentaram sugestões e/ou críticas referentes ao Projeto e sua continuidade.

\subsection{Contribuições do Projeto de Extensão Lapidar para os discentes e os egressos}

Com a aplicação do questionário, foram obtidos resultados referentes à percepção da equipe do Projeto sobre a contribuição do Lapidar para suas ações nos estágios, nos trabalhos e nas futuras atuações profissionais. No Quadro 1, apresentam-se algumas respostas de discentes e/ou egressos que participaram do projeto.

Ao analisar as respostas dos participantes no Quadro 1, constatou-se que o projeto ampliou a percepção dos fazeres biblioteconômico e arquivístico para além das atividades tradicionais de tratamento e organização da informação, a fim de promover, de maneira dialógica e interativa, a construção do conhecimento. Em sua fala, o Respondente 2 demonstra 
o despertar para o sentido do papel do mediador, quando menciona a aproximação entre a informação e o usuário por meio da interferência do bibliotecário. Também vale ressaltar a percepção dos respondentes sobre a necessidade de planejar as ações de mediação, o que possibilita traçar objetivos e adotar métodos e estratégias, a fim de perceber os resultados alcançados. Nesse sentido, pode-se inferir que, ao planejar uma atividade de mediação da leitura, o profissional age sistematicamente, para evitar ações inconsistentes e conseguir analisar e avaliar suas ações.

Nas falas dos respondentes (Quadro 1), fica evidente sua inquietação para experimentar e compreender a relação entre a teoria e a prática no contexto acadêmico. $O$ projeto de extensão possibilita a junção com os outros dois pilares da Universidade:o ensino e a pesquisa, que são indissolúveis quando as ações de extensão são elaboradas a partir do processo de ensino e como se baseiam e geram pesquisas. A fala do Respondente 3 indica que a prática executada nas ações do Lapidar possibilitou a aproximação da teoria com a prática e ampliou a compreensão sobre a responsabilidade social do arquivista.

\section{Quadro 1-}

Percepção da equipe do Projeto sobre a contribuição do Projeto Lapidar para sua formação

Respondente 2- "O Projeto Lapidar me fez compreender que o profissional bibliotecário tem que estar apto para contribuir para a construção de leitores, desempenhando o papel de mediador entre o acervo e sua comunidade. O profissional da informação tem que procurar desenvolver projetos de incentivo e prática a leitura, assim esse profissional poderá contribuir para a construção de novos leitores na sociedade. Ou seja, profissionais da área da ciência da informação têm que estar atentos para necessidades de leitura e formação de leitores promovendo ações que contribuam para o prazer de ler, e assim, construindo na sociedade novos leitores."

Respondente 3-“Embora eu ainda esteja no $1^{\circ}$ semestre do Curso de Arquivologia, tenho consciência do papel do arquivista, sobretudo como gestor da informação, na sociedade. Os professores estão, a todo momento, enfatizando a responsabilidade social que nós, ainda enquanto formandos, temos. Uma discussão recorrente na minha turma é a abordagem teórica, em nossa área, com muito mais ênfase que a abordagem prática. Discutimos sobre nossas funções e deveres, mas hora não temos tempo para praticar, hora não temos interesse nem oportunidades. Foi por meio do lapidar que tive o primeiro contato do fazer do meu curso e tive consciência do quão importante é trocar conhecimento para nossa formação, não só como profissional, mas também quanto pessoa."

Respondente 4-"Acredito que a maior contribuição que o projeto trouxe foi demonstrar que a Biblioteconomia é muito maior do que é ensinada em sala de aula. Para a minha formação acadêmica, toda troca de experiências com o pessoal da Biblioteca Comunitária, as conversas do grupo, cada palestra (que pude participar), toda a sensibilidade demonstrada por todos os envolvidos mostrou que somos (e talvez seremos) profissionais em eterna construção estaremos sempre aprendendo a nos tornar pessoas melhores no trabalho, na academia e na vida."

Respondente 5-“A contribuição foi rica, e dinâmica no qual pude mostrar alguns nuances da "arte abstrata" visando um aprendizado mais amplo com todos os envolvidos neste projeto de arte/educação."

Fonte: Dados da pesquisa, 2017. 
Ainda no que se refere ao Quadro 1, a sala de aula, muitas vezes, "molda" as expressões do sujeito em uma formalidade acadêmica, fazendo com que ele se expresse de maneira textual ou oral, ou seja, os discursos ancorados cientificamente de "modo formal". Por outro lado, a extensão acolhe esses tipos de expressão formal e amplia a possibilidade de o sujeito se posicionar de modo artístico, com ações ligadas à música, à pintura, aos desenhos, aos gestos, enfim, a todas as ações subjetivas que ele possa expressar e representar o seu conhecimento, suas habilidades e seu desejo. O Respondente 5 , por exemplo, que é um artista, manifesta-se por meio de artes abstratas e encontrou no Lapidar um ambiente propício para se desenvolver por meio de suas práticas, demonstrando suas habilidades nas ações de extensão.

Quanto ao Quadro 2, apresenta a percepção dos participantes do Projeto Lapidar, a ampliação das habilidades e das competências para atuar nos estágios/trabalho e perspectivas como profissionais da informação. $O$ estudo mostrou que o Respondente 1 sempre esteve em um contexto propício à mediação, como é o ambiente da escola, especialmente o da sala de aula, e a experiência do projeto de extensão influenciou seu comportamento, pois a vivência do Lapidar propiciou um amadurecimento que gerou autoconfiança para contribuir com o próprio espaço de fala, uma vez que suas competências se tornaram visíveis para os demais.

Na fala do Respondente 2, percebe-se a relevância do papel do bibliotecário nessas ações mediadoras, o qual atua para além do espaço físico da biblioteca, já que pode atrair quem está fora desse espaço, como, por exemplo, na comunidade, agindo com um olhar social sobre o ambiente, como um sujeito protagonista, como reflete Almeida Júnior (2014, p. 111), ao informar que as ações de mediação estão presentes no fazer diário dos profissionais da informação.

Quanto ao Respondente 3, é evidente a vivência profissional em que está inserido, em que as competências e as habilidades já estavam presentes. Porém, por meio do Projeto, houve uma aplicação das ações em que o sujeito tomou consciência do seu fazer. Há, ainda, indícios da formação do protagonismo social, porque a estudante disse que deseja ser generosa, assim como foram com ela, independentemente do ambiente onde esteja e do papel que esteja cumprindo. Ao perceber o acolhimento, a generosidade e o desejo de agir da mesma maneira, ela passa a se posicionar e a desejar um novo papel - o de ser multiplicadora dos elementos de que conseguiu se apropriar. Assim, já tem consciência de que deseja se tornar protagonista. 
Quadro 2-

Ampliação das habilidades e das competências para atuar nos estágios/trabalho e as perspectivas como profissional da informação

Respondente 1 -“A integração dos professores em projeto de leitura na escola onde trabalho.”

Respondente 2-“O projeto de extensão LAPIDAR contribuiu para o meu conhecimento e me fez entender que como mediadora da informação tenho que buscar exercer o papel de incentivador da leitura, fazendo com que meus usuários despertem o prazer pela leitura, realizando ações em conjunto não só com a biblioteca ou instituição em que atue, mas também com a comunidade, desenvolvendo projetos sociais que visem o incentivo da prática leitura, buscando atender ao um público geral, independente da idade, sexo, nível social ou religião, etc."

Respondente 3- "Eu já trabalho com crianças e foi um privilégio muito grande participar do Lapidar, principalmente com ações voltadas para crianças e adolescentes, que são meu público profissional. 0 Lapidar, a cada encontro, me trouxe uma série de aprendizado, desde palestras com importantes pessoas da área, até as ricas dinâmicas e rodas de leitura que tivemos. A professora e todo o grupo me acolheram de forma generosa e eu sinto que essa é uma das principais características para uma profissão dessa área. Quero ser generosa em qualquer lugar que eu esteja, seja como mediadora ou qualquer outra função que atue."

Respondente 4-"O contato com a Biblioteca Comunitária apontou que atividades lúdicas podem auxiliar a mediação com a leitura, evidentemente respeitando a faixa etária do público e um planejamento estratégico. Tudo isso auxiliado por uma postura do (futuro) profissional bibliotecário fora da sua zona de conforto colocando-se a disposição através de interação e improviso contínuo com o seu público, estes ensinamentos vou levar a vida toda com muito carinho."

Respondente 5-“Organização sistemática e estratégica envolvendo arte educação. Implementação e novas formas de interação com a comunidade. Exercício constante do 'fazer artístico' e suas múltiplas possibilidades. Novas perspectivas utilizando linguagens simples e eficiente, e com um olhar mais apurado disseminando uma nova pedagogia."

Fonte: Dados da pesquisa, 2017.

Em suas falas, os Respondentes 4 e 5 (Quadro 2)demonstraram que têm consciência de que é necessário planejar as ações a serem desenvolvidas, ou seja, compreendem que a mediação da leitura tem um contexto formativo na composição de sua organização e estruturação. Por outro lado, quando a Respondente 4 se refere ao improviso, parece contradizer-se, pois afirma anteriormente que é importante sistematizar as ações. Pode-se inferir que a estudante torna evidente que o mediador de fato vai além das expectativas e é movido justamente por essa aproximação com o público, que infere no sujeito a tomada de decisão, depois de constatar que, naquele contexto, ocorreram alterações comportamentais de forma rápida, o que requer desse profissional uma postura estratégica por meio de um planejamento eficiente.

Quanto ao Quadro 3, os participantes avaliaram suas ações no Projeto Lapidar e apresentaram sugestões para as próximas edições. A partir da análise da afirmação realizada pelo Respondente 1, pode-se inferir que, ao ressaltar sobre a necessidade de consultar materiais bibliográficos, demonstra que a prática proporcionou novos conhecimentos e 
demandou do sujeito novos questionamentos, o que o fez sentir a necessidade de retomar as bases teóricas. Assim, pode-se entender que, a partir da prática do Projeto Lapidar, o sujeito se apropriou das informações apresentadas em sala de aula e/ou em pesquisas, o que gerou novos conflitos informacionais.

Já o Respondente 2 (Quadro 3) reflete sobre a realização de novas práticas e a adoção de outros recursos a serem utilizados para as ações na biblioteca comunitária, como fantoches, espetáculos teatrais, entre outros. No que se refere ao uso desses recursos, de maneira integrada, pode-se perceber uma consonância com a afirmação de Gomes (2017), quando enuncia que a informação deve ser entendida como um processo, por sua condição integrativa entre a representação física (coisa) e o conteúdo intangível (conhecimento). Dessa maneira, o mediador da informação deve se apropriar de dispositivos que conferem sentido e significado aos sujeitos, para que, ao serem apresentados nos jogos simbólicos da troca de informações, também se tornem representativos dessa ação. Exemplo disso é, quando se utiliza um fantoche que tem características regionais e a contação de história se refere às atividades culturais da região do usuário, esse fantoche passa a ser um dispositivo que auxiliará os sujeitos a compreenderem os valores identitários e a se apropriar das informações que são disponibilizadas nesse processo.

Pode-se compreender, ainda, que a afirmação do Respondente 2 visa criar novas ações para atrair os usuários potenciais e, especialmente, chamar à atenção de crianças com idades entre quatro e oito anos. Esse comportamento pode ser entendido como o resultado da ampliação do olhar, voltado para as características e as necessidades dos usuários e a preocupação, como futuro mediador da informação, de acolher os diferentes usuários.

Quadro 3-

Avaliação e sugestões dos participantes das ações do Projeto Lapidar

Respondente 1 -“A prática da consulta a livros especializados.”

Respondente 2-“As próximas ações do projeto poderiam utilizar: fantoches; espetáculos teatrais; palestras - como desperta o gosto pela leitura; jogos de leitura -existem vários jogos que incentivam a leitura- para assim, estimular a leitura aos usuários de menor idade."

Respondente 3-“Ampliação de carga horária. Precisamos de mais momentos na semana, um só não é suficiente para tantas ideias e tanto aprendizado. Também precisamos de mais pessoas comprometidas com o projeto, acho que a ampliação da carga horária semanal vai possibilitar que todos os interessados possam participar e adequar seus horários, já que temos horários diferentes. Eu que me sinto grata por tudo!!!

Espero que o projeto continue e cresça ainda mais. Você e nós merecemos isso."

Respondente 5- "Criar um Teatro de Máscaras de papel, feitas pelos/as próprios/as alunos/as. Criar personagens para interagir com os alunos/as. Espero ter contribuído positivamente com as questões. Até breve!!! Utilizar filmes, docs, é desnecessário, pois reduz o tempo das nossas apresentações."

Fonte: Dados da pesquisa, 2017. 
Ainda analisando o Quadro 3, pode-se inferir que a fala do Respondente 3, quanto à sugestão sobre o aumento da carga horária, demonstra o desejo de vivenciar e ter mais contato com as ações desenvolvidas no Projeto. Essa fala ratifica a importância de se extrapolarem os limites da sala de aula para que, ainda no processo de formação, o sujeito tenha mais experiências e conhecimentos práticos. Por outro lado, além dos limites físicos, a Respondente 3 menciona a ampliação de carga horária, o que refletiria na possibilidade de atrair novos participantes para o Projeto. Pode-se compreender que esse desejo está ligado à vontade de que outros sujeitos possam vivenciar a experiência que ela teve, além de sua própria necessidade de ampliar essas ações que puderam desenvolver.

O relato do Respondente 5, ainda no Quadro 3, equipara-se à sugestão do Respondente 2, quanto ao uso de outros recursos. Ele também descreve outras estratégias para estimular a criatividade e a imaginação dos usuários. Contudo, critica a exibição de filmes (longa-metragem) por compreender que demanda um período maior de concentração. No entanto, o filme se configura como um recurso significativo por agregar texto, som e imagem em ação e por ser considerado como um recurso informacional e pedagógico. A inferência realizada pelo respondente não invalida o sentimento de expectativa das futuras edições do Projeto, ao expressar: "Até breve!", evidenciando o desejo de continuar vinculado ao Projeto. Quando os discentes, os egressos e os agentes mediadores da Biblioteca Comunitária manifestam o desejo de continuar como Projeto, é que as professoras/coordenadoras planejam as próximas edições, em que serão consideradas as críticas e as sugestões apresentadas neste estudo.

A partir das avaliações parciais e finais, quanto à formação de mediadores, foi constatada a oportunidade de identificar as habilidades dos membros participantes do projeto e a possibilidade de desenvolver novas competências, que abrangem a desenvoltura para falar em público; a criação de estratégias para fazer as atividades que não foram planejadas; a construção de histórias, tanto com a produção textual quanto com a prática oral; a promoção de programação cultural e, essencialmente, a percepção da necessidade individual e coletiva dos sujeitos, com a demonstração de afeto, proatividade e acolhimento.

Também foram identificados pontos positivos ligados à formação de leitores, como: o fato de receberem as atividades desenvolvidas pelos membros do projeto; os indícios de que o conhecimento foi ampliado, como ficou evidente, por exemplo, na produção textual sobre os traços identitários de Salvador, com a realização de uma peça teatral, e os indicativos de que o gosto pela leitura foi estimulado.

Assim, por meio do processo avaliativo, foi possivel reconhecer que a mediação entre a informação e o usuário é complexa e que é preciso refletir sobre essa ação, tendo como 
parâmetros a análise do sujeito, do ambiente e do fazer como profissional da informação, este último ancorado nas técnicas e nas teorias da área.

\section{Considerações finais}

Os resultados desta pesquisa evidenciaram as etapas das atividades realizadas pelo Projeto Lapidar para formar leitores e mediadores da leitura. Foi possível compreender a importância de realizar práticas para além da sala de aula, estabelecendo redes de parcerias, especialmente com ambientes e profissionais da informação. De modo específico, percebeu-se que as atividades de mediação da leitura devem contemplar ações de qualificação, planejamento e realização das atividades de maneira consciente e com abertura para atividades criativas e avaliação das ações.

Se, de um lado, depois das etapas de qualificação desses participantes, foi possível colocar em prática os conceitos teóricos e sistemáticos aprendidos na Universidade, de outro, foi possível se apropriar desses conceitos e desenvolver novos conhecimentos no encontro com a comunidade e com o cenário prático. Nesse encontro, além do amadurecimento dos participantes, o Projeto propiciou um retorno à Comunidade, quando potencializou o acesso, o uso e apropriação da informação, por meio das ações de leitura, auxiliando-os a desenvolver o prazer de ler. Assim, o Lapidar cumpriu o papel de uma atividade de extensão ao fortalecer os laços entre a Universidade e a Comunidade.

Quanto à apropriação da informação, os resultados indicam que existem indícios do protagonismo social, tanto por parte dos participantes da pesquisa, que se qualificaram como mediadores da leitura, quanto dos novos leitores, que participaram das ações de mediação da leitura. Esse protagonismo fica mais claro quando os participantes já multiplicam ações em seus ambientes, para além da Biblioteca Comunitária, realizando ações de leitura em seus estágios e trabalhos ou tendo consciência de como se realiza o fazer do mediador da informação e da leitura.

\section{Referências}

ALMEIDA JUNIOR, Oswaldo Francisco de. Bibliotecas públicas e bibliotecas alternativas. Londrina: Editora UEL, 1997.

ALMEIDA JUNIOR, Oswaldo Francisco de; SANTOS NETO, João Arlindo. Mediação da informação e a organização do conhecimento: interrelações. Informação \& Informação, Londrina, v. 19, n. 2, p. 98-116, maio/ago., 2014. Disponível em: http://www.uel.br/revistas/uel/index.php/informacao/article/view/16716/pdf 25 Acesso em: 14 fev. 2019. 
BARBOSA, Ricardo Rodrigues. Gestão da Informação e do Conhecimento: origens, polêmicas e perspectivas. Informação \& Informação, Londrina, v. 13, n. esp., p. 1-25, 2008.

BORTOLIN, Sueli. Mediação oral da literatura: a voz dos bibliotecários lendo ou narrando. 2010. 234 f. Tese (Doutorado em Ciência da Informação) - Faculdade de Filosofia e Ciências, Universidade Estadual Paulista, Marília, 2010. Disponível em: http://hdl.handle.net/11449/103349 Acesso em 14 fev. 2019.

CARVALHO, Marlene. Alfabetizar e letrar: um diálogo entre a teoria e a prática. Petrópolis, RJ: Editora Vozes, 2005.

GARRAFA, Volnei (Org.). Extensão: a universidade construindo saber e cidadania: relatório de atividades, 1987/1988. Brasília: Ed. UNB, 1989.

GOMES, Henriette Ferreira. A dimensão dialógica, estética, formativa e ética da mediação da informação. Informação \& Informação, Londrina, v. 19, n. 2, p. 46-59, out. 2014. ISSN 19818920.

http://www.uel.br/revistas/uel/index.php/informacao/article/view/19994/19090 Acesso em: 9 set. 2017.

GOMES, Henriette Ferreira. Mediação da informação e protagonismo social: relações com vida ativa e ação comunicativa à luz de Hannah Arendt e Jürgen Habermas. In:GOMES, Henriette Ferreira; NOVO, Hildenise Ferreira (Org.) Informação e protagonismo social. Salvador: EDUFBA, 2017. p. 27- 43.

KATO, Mary Aizawa. O aprendizado da leitura. São Paulo: Martins Fontes,1999.

MACHADO, Elisa Campos. Identidade cultural de Heliópolis: biblioteca comunitária. Informação \& Sociedade: Estudos. João Pessoa, v. 15, n. 2, p. 113-125, jul./dez. 2005.

MACHADO, Elisa Campos. Uma discussão acerca do conceito de biblioteca comunitária. Revista Digital de Biblioteconomia e Ciência da Informação, Campinas, v. 7, n. 1, p. 80-94, jul./dez. 2009.

PETIT, Michèle. Os jovens e a leitura: uma nova perspectiva. São Paulo: Editora 34, 2008. 